\title{
Symposium review: The relevance of bovine milk phospholipids in human nutrition-Evidence of the effect on infant gut and brain development*
}

\author{
Joana Ortega-Anaya and Rafael Jiménez-Flores† \\ Food Science and Technology Department, The Ohio State University, Columbus 43210
}

\section{ABSTRACT}

This paper reflects the concepts reviewed during the presentation in the Joint MILK/Lactation Biology Symposium at the ADSA 2018 Annual Meeting. Our intention is to update the concepts and advances in the area of research regarding milk phospholipids or polar lipid fraction as part of a dairy ingredient used today in nutritional studies that focus on gut health as well as brain development of infants. Although processing advances have allowed the production of novel ingredients rich in milk fat globule membrane (MFGM) components, mostly monitored by phospholipid concentration and presence of membrane proteins, there is wide variability in their composition and structure. Furthermore, we aimed to include in the phospholipid fraction of milk nanovesicles designated as milk exosomes, which are secreted into milk by different secretion mechanisms than those of the fat globules but are also made up of a unique mixture of polar lipids. We consider imperative the study of polar lipid-derived structures from milk regarding composition and structure to gain insights into their biological effect in human health. Nevertheless, and tolerating the differences in composition and concentration of their components, studies supplementing the diet of infants with polar lipids (i.e., MFGM components) have shown significant advances in several areas of human health and well-being. Here we present a summary of the important components of MFGM and milk exosomes as well as an overview of the effects on gut health and brain and cognitive development when added to the diet of infants.

Key words: milk fat globule membrane, phospholipid, exosome, brain development, gut health

Received July 6, 2018.

Accepted September 18, 2018.

* Presented as part of the Joint MILK/Lactation Biology Symposium: Milk Globules, Vesicles, and Exosomes-Update, Origin, Structure, and Function at the ADSA Annual Meeting, Knoxville, Tennessee, June 2018.

†Corresponding author: jimenez-flores.1@osu.edu

\section{INTRODUCTION}

Milk has always been considered a very interesting mammalian fluid due to its molecular, physicochemical, and structural complexity. To date, many components of both human and bovine milk still pose questions regarding their structure, function, role, and biological significance to human health. One of those components is phospholipids, which are a complex mixture of more than 30 molecular species of phosphatidylcholine (PC), phosphatidylethanolamine (PE), phosphatidylserine (PS), phosphatidylinositol (PI), and sphingophospholipids that have been clearly identified within the bovine milk fat globule membrane (MFGM; Contarini and Povolo, 2013). Phospholipids are found in 2 fractions of milk: MFGM, which accounts most of the phospholipids in milk constituting the trilayer membrane surrounding each fat globule (Gallier et al., 2010, 2014; Lopez et al., 2010), and nanovesicles, which are secreted into milk by the mammary gland cells and are implicated in cellto-cell communication by means of their functionally active cargo (e.g., mRNA, microRNA, and different proteins; Zempleni et al., 2017).

This assortment of lipids organized in both the MFGM and nanovesicles is unique in milk and has been found to have a positive effect in many aspects of human health by various mechanisms. Two main beneficial health effects - benefit to the intestinal cells via leaky gut syndrome studies and several brain development and cognitive improvements - have been studied by more than one group each. This review presents a compact overview of interesting aspects of milk phospholipid fractions and their role in intestinal health and brain development as observed by the authors.

\section{COMPOSITION OF MILK PHOSPHOLIPIDS}

Phospholipids are ubiquitous molecules in membranes and vesicles, and milk seems to possess a unique mixture of them. They are classified as polar lipids and chemically are amphiphilic molecules that consist of a hydrophobic tail, given by fatty acids, and a hydrophilic head, given by a specific polar group. In general, 2 main 
Phosphatidylcholine

(PC)

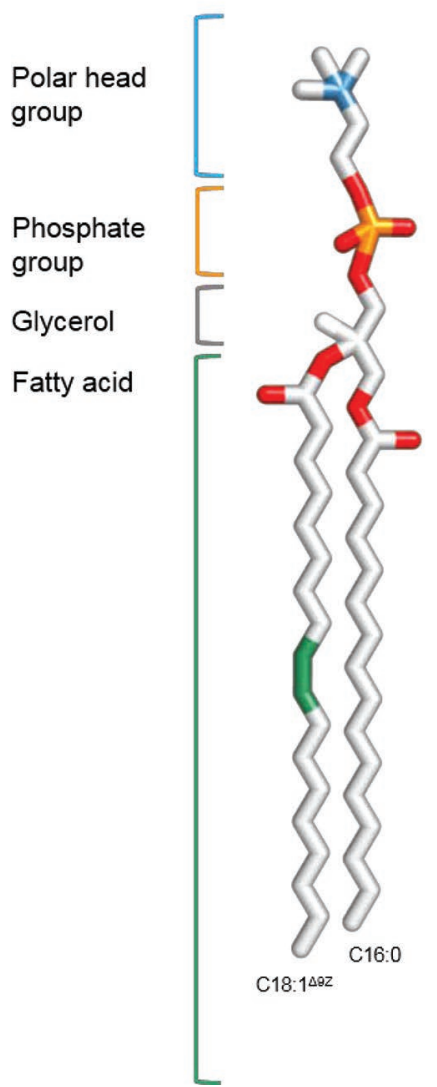

Phosphatidylethanolamine

(PE)

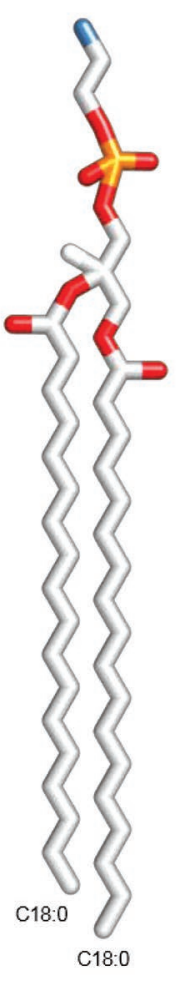

Phosphatidylserine

(PS)

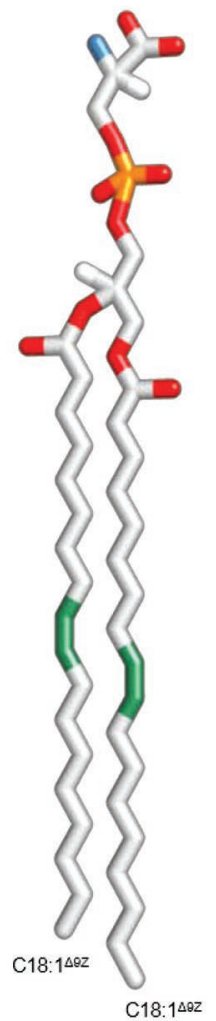

Phosphatidylinositol
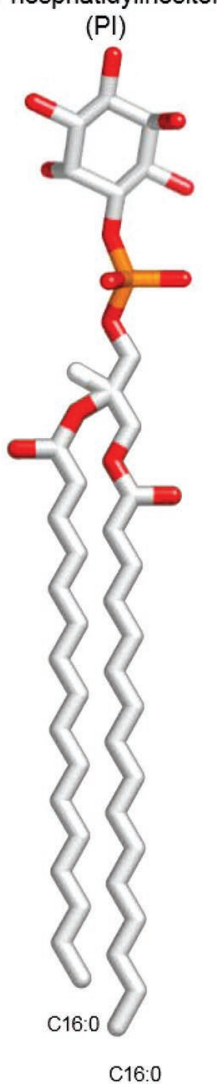

Figure 1. Structure of glycerophospholipids found in milk and the predominant families based on the polar head group. Atomic color code: $\mathrm{C}=$ gray, $\mathrm{H}=$ white, $\mathrm{O}=$ red, $\mathrm{N}=$ blue, $\mathrm{P}=$ orange; double bonds are depicted in green.

classes of phospholipids are found in milk (Contarini and Povolo, 2013). The first is glycerophospholipids, which are formed by a glycerol molecule esterified by 2 fatty acids and a phosphoric acid molecule, which in turn is bound to additional polar groups (choline, serine, ethanolamine, or inositol). Figure 1 depicts the main groups or families of glycerophospholipids based on the chemical composition of their polar groups.

The second most important group of polar lipids found in milk is sphingolipids, which comprise a sphingosine backbone (2-amino-4-octadecene-1,3-diol) sometimes bound to a fatty acid (through an amide bond) and a polar head. The polar groups usually found in milk vary greatly and include carbohydrates (glucose, galactcose, and lactose), which are referred to as glycoceramides (Figure 2; Contarini and Povolo, 2013). However, sphingomyelin is the dominant species. It comprises a phosphocholine head group; due to this, it is usually classified as a sphingophospholipid and included in the phospholipid fraction (Figure 2; Contarini and Povolo, 2013).
Sphingomyelin ( $\mathbf{S M}$ ) is a very important constituent of the phospholipid fraction of milk due to its high concentration in the MFGM and its implication in many beneficial effects on human health, such as neuronal development in infants and protection of neonates from bacterial infections (Bourlieu et al., 2015; Claumarchirant et al., 2016; Murthy et al., 2016). Last, gangliosides are another kind of sphingolipid that are recently getting attention owing to their potential bioactivities in brain function and the immune system, among others (Rueda, 2013). They possess highly complex polar head groups constituted by one or more sialic acid units in addition to oligosaccharides (Ma et al., 2015).

The concentration and composition (polar head and fatty acid tail) of glycerophospholipids and sphingolipids in bovine raw milk are greatly affected by different factors, including breed of the cow, stage of lactation, season of the year, nutrition and diet, and processing and treatment. Interestingly, the analytical methods of extraction and analysis add variation in determining the content of the polar lipid fraction (Bitman and 


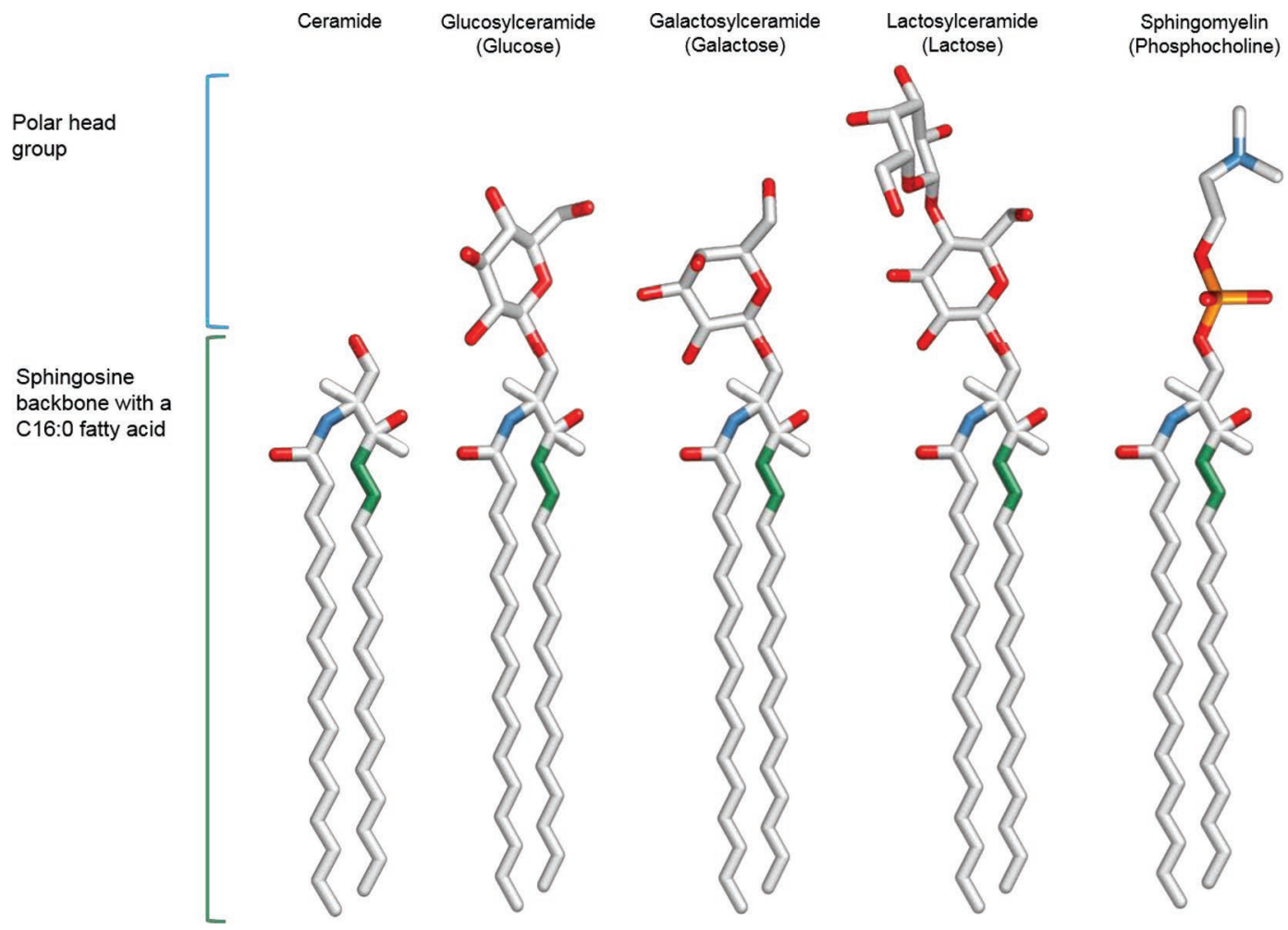

Figure 2. Structure of the most common sphingolipids found in milk based on the polar head group. The sphingosine backbone (right chain in each structure) is depicted here bound to a palmitic acid (left chain). Atomic color code: $\mathrm{C}=$ gray, $\mathrm{H}=$ white, $\mathrm{O}=$ red, $\mathrm{N}=$ blue, $\mathrm{P}=$ orange; double bonds are depicted in green.

Wood, 1990; Avalli and Contarini, 2005; Rombaut and Dewettnick, 2006; Graves et al., 2007; Rombaut et al., 2007; Lopez et al., 2008; Contarini and Povolo, 2013; Pimentel et al., 2018). Overall, the concentration of the polar lipid fraction ranges between 9 and $40 \mathrm{mg} / 100$ $\mathrm{g}$ of raw milk (Table 1). The predominant species are $\mathrm{PE}, \mathrm{PC}$, and SM, accounting for approximately $80 \%$ of total polar lipids. An interesting aspect to highlight is the concentration ratio of $\mathrm{PC}$ and SM. It can be seen from Table 1 that they keep a 1.0 to 1.1 ratio with the exception of the data reported by Kiełbowicz et al. (2013), where the SM content is significantly lower than that of PC. These results could be the product of using charge aerosol detection coupled with liquid

Table 1. Composition of the polar lipid fraction $(\mathrm{mg} / 100 \mathrm{~g}$ of milk) of raw milk

\begin{tabular}{|c|c|c|c|c|c|c|c|}
\hline \multirow{2}{*}{$\begin{array}{l}\text { Polar lipid } \\
\text { fraction }\end{array}$} & \multicolumn{5}{|c|}{$\begin{array}{c}\text { Phospholipid species }{ }^{1} \\
\text { (mg/100 mg of polar lipid fraction) }\end{array}$} & \multirow{2}{*}{$\begin{array}{l}\mathrm{PC} / \mathrm{SM} \\
\text { ratio }\end{array}$} & \multirow[b]{2}{*}{ Reference } \\
\hline & $\mathrm{PE}$ & $\mathrm{PC}$ & $\mathrm{SM}$ & PS & PI & & \\
\hline 20.4 & 31.0 & 28.0 & 28.7 & 8.1 & 4.1 & 1.0 & Bitman and Wood, 1990 \\
\hline 10.5 & 26.8 & 22.0 & 21.6 & 16.1 & 13.6 & 1.0 & Lopez et al., 2008 \\
\hline 23.0 & 34.2 & 25.4 & 23.6 & 2.8 & 6.2 & 1.1 & Christie, 1987 \\
\hline 29.0 & 42.0 & 19.2 & 18.0 & 6.7 & 4.8 & 1.1 & Rombaut et al., 2005 \\
\hline 40.0 & 31.5 & 26.0 & 23.8 & 8.8 & 4.9 & 1.1 & Rombaut et al., 2006 \\
\hline 33.6 & 33.2 & 27.4 & 25.1 & 9.3 & 5.2 & 1.1 & Rombaut et al., 2006 \\
\hline 24.5 & 46.4 & 21.1 & 19.8 & 7.4 & 5.3 & 1.1 & Rombaut et al., 2007 \\
\hline 24.2 & 36.9 & 27.0 & 23.7 & 6.3 & 6.1 & 1.1 & Le et al., 2011 \\
\hline 35.0 & 31.1 & 37.3 & 28.0 & 3.1 & 0.6 & 1.3 & Garcia et al., 2012 \\
\hline 9.4 & 32.3 & 27.3 & 20.5 & 10.5 & 9.3 & 1.3 & Avalli and Contarini, 2005 \\
\hline 31.3 & 33.4 & 43.2 & 5.1 & 8.1 & 10.3 & 8.5 & Kielbowicz et al., 2013 \\
\hline
\end{tabular}

${ }^{1} \mathrm{PE}=$ phosphatidylethanolamine; $\mathrm{PC}=$ phosphatidylcholine; $\mathrm{SM}=$ sphingomyelin; $\mathrm{PS}=$ phosphatidylserine; PI = phosphatidylinositol. 
chromatography, a recently developed method that provides greater sensitivity and better precision than techniques such as UV, fluorescence, refractive index, and evaporative light scattering detection (Hazotte et al., 2007; Kielbowicz et al., 2013).

Phosphatidylcholine represents up to $35 \%$ of the total phospholipids, and its function is to maintain the permeability of the membrane (Dewettinck et al., 2008; Jimenez-Flores et al., 2009) due to its flexible morphology. Depending on the water concentration and temperature, $\mathrm{PC}$ can associate into 1 of the 4 possible phases, including lamellar crystalline, laminar $\beta^{\prime}$, laminar $\alpha$, and oblique $\beta^{\prime}$ (Fedotova and Lencki, 2008). Phosphatidylethanolamine constitutes up to $30 \%$ of the total phospholipids in the MFGM and is mostly bound to UFA (68\%) with high levels of C18:1 and C18:2 and less C14:0 and C16:0 (Sanchez-Juanes et al., 2009). Phosphatidylinositol and PS are present in lower concentrations in milk. They are anionic phospholipids that are distributed asymmetrically throughout the inner monolayer of MFGM (Deeth, 1997).

The classification of phospholipids and phosphosphingolipids in milk described so far is based on the polar head group, but higher complexity derives from the wide variety of fatty acids bound to either the glycerol or sphingosine backbone. It includes chain lengths from C2 through C24, SFA, MUFA, and PUFA as well as n-3, n-6, and n-9. According to the data shown in Table 2, the most predominant species are $\mathrm{C} 16$ to $\mathrm{C} 18$, SFA and MUFA with low concentrations of $\mathrm{C} 4$ to $\mathrm{C} 8$, and PUFA (Lopez et al., 2008).

As can be inferred from the information presented here, the composition of the polar lipid fraction of milk is anything but simple. Moreover, the chemical composition of these lipids has a direct effect on the molecular structure and organization into the different vesicles

Table 2. Fatty acid composition of glycerophospholipids and sphingolipids from milk

\begin{tabular}{lc}
\hline Fatty acid fraction & $\begin{array}{c}\text { Abundance } \\
\text { (\% of polar lipid fraction) }\end{array}$ \\
\hline Fatty acid by chain length & \\
C4-C8 & $2.1-2.3$ \\
C10-C15 & $11.6-17.3$ \\
C16-C18 & $74.5-79.1$ \\
C20-C24 & $5.9-7.2$ \\
Fatty acid by saturation & $55.2-67.0$ \\
SFA & $33.0-44.8$ \\
UFA & $25.8-36.9$ \\
MUFA & $7.2-7.9$ \\
PUFA & $4.5-5.7$ \\
n-6 PUFA & $0.6-1.9$ \\
n-3 PUFA &
\end{tabular}

${ }^{1}$ Including eicosapentaenoic acid and docosahexaenoic acid. found in milk (namely the MFGM and nanovesicles). This has been studied for milk SM in various biomimetic models, where it has been proven that because of its structure (and in combination with cholesterol), it forms liquid ordered-phase domains in the external layer of the MFGM, laterally segregated from the rest of the phospholipids into lipid rafts, in analogy with mammalian plasma membranes (Lopez et al., 2010; Guyomarc'h et al., 2017). Furthermore, the fatty acid length bound (24:0 and 16:0) determines the height of the domain because it causes a mismatch, which in turn defines the internal organization and topography of the vesicle (Garner et al., 2007; Guyomarc'h et al., 2014, 2017). The heterogeneous packing of milk SM and its structural domain is now thought to have a biological implication in regulating different mechanisms in the MFGM, such as recognition and binding of bacteria, enzymes, and other proteins, or, alternatively, participate in the physical stability of phospholipid vesicles (Guyomarc'h et al., 2017).

Milk phospholipids are found as constituents in mainly 2 structures in milk: the MFGM, which are synthesized and secreted alongside with fat globules during lactation, and milk exosomes (MEX), which are nanovesicles secreted into milk by the mammary gland cells by mechanisms completely different than those of the fat globules.

A high number of studies have reported the composition, structure, function, biosynthesis, and biological function of the MFGM. It is a complex structure that surrounds the fat globules, imparting stability, protection, and selectivity toward enzymes, ligands, and receptors. The MFGM comprises a trilayer of heterogeneously distributed proteins and polar lipids (20-60\% protein and $80-40 \%$ polar lipids) with a thickness between 10 and $50 \mathrm{~nm}$ (Keenan and Mather, 2006). The inner or primary monolayer is in direct contact with the triglycerides from the fat globule (Vanderghem et al., 2011) and comprises mostly PE, PS, and PI derived from the endoplasmic reticulum and the cytoplasm of the lactating cell during its biosynthesis (Deeth, 1997). The outer bilayer, which is derived from the apical plasma membrane of epithelial mammary cells, has lower concentrations of PE, PS, and PI and high concentrations of PC, SM, cholesterol, and gangliosides (Deeth, 1997; Lopez et al., 2008). An additional glycocalyx that varies during lactation is associated with this outer bilayer, which acts as a source of ligands and binding sites for bacteria and viruses (Spitsberg and Gorewit, 1997; Evers, 2004; Wilson et al., 2008). Interactions among MFGM constituents and other molecules occur mainly on this outer surface (Vanderghem et al., 2011). Detailed information and schematic representations of 
the structure of the MFGM have been already published (Gallier et al., 2010, 2014; Singh and Gallier, 2017).

In contrast with the vast number of publications regarding structure and biological effects of the MFGM, a new group of vesicular structures found in milk are getting more and more attention for their potential effects on human health. Milk exosomes are cell-released phospholipid vesicles ranging from 30 to $120 \mathrm{~nm}$ in diameter and with a density of 1.13 to $1.19 \mathrm{~g} / \mathrm{mL}$ (Zhang et al., 2014) that enclose a variety of cargo, including mRNA, microRNA, long noncoding RNA, DNA, and proteins. In milk, both human and bovine, MEX have been shown to transfer their RNA-derived cargo to immune cells to potentially modulate immune cell function (Lakkaraju and Rodriguez-Boulan, 2008; Hata et al., 2010; Zempleni et al., 2017). In general, exosomes and nanovesicles are secreted by both eukaryotic and prokaryotic cells (via exocytosis of multivesicular bodies) into the environment for cell-to-cell communication, protection, and exchange of genetic information (Nieuwland and Sturk, 2010; Colombo et al., 2014; Kalra et al., 2016; Rani et al., 2017). They dock on to the surfaces of recipient cells, where they transmit signals from the cell surface and transfer their contents to produce functional responses (French et al., 2017). This mechanism, though critical, is a poorly understood process thought to be mediated mostly by the proteins and genetic material, which in turn, is dependent on the parent cell (French et al., 2017). However, is has recently become evident that the bioactivity of exosomes resides not only in the latter molecules but also in their lipidic content. In general, the lipids present in exosomes are similar to those found in cellular membranes: cholesterol, phospholipids, and sphingolipids. They are enriched in PC, SM, and PE (Subra et al., 2010). However, the specific concentration and their organization in lipid domains and rafts are completely determined by the parent cell (Skotland et al., 2017). Studies performed in human-derived exosomes from many types of cells (i.e., B-lymphocytes, reticulocytes, and mast and dendritic cells) indicate that phospholipids are asymmetrically distributed in the bilayer (Skotland et al., 2017). Sphingomyelin, other sphingolipids, and PC are expected to be in the outer layer, whereas the rest of the phospholipids are expected to be mainly in the inner layer of the membrane (van Meer et al., 2008). This distribution is prone to be modified by the presence of different proteins and enzymes, and, as a result, the affinity or selectivity of the exosomes might be affected (Clark, 2011; Hankins et al., 2015).

It is important to point out that the majority of studies regarding lipid composition and structure of exosomes have been performed in human-derived nanovesicles. To date, little to no information about exosomal bovine lipids from milk has been reported. This opens a window of research opportunities because evidence suggests that dietary MEX are bioavailable and that they deliver their cargo to peripheral tissues in humans (Kusuma et al., 2016; Zempleni et al., 2017). Once the MEX reach the intestinal mucosa, 2 processes occur: (1) they are disassembled for subsequent transfer of cargo to endogenous exosomes, and (2) they are transported intact through the mucosa, reaching the liver, spleen, and kidneys for further distribution to tissues (Zempleni et al., 2017). The fate of the lipids and proteins of MEX would be hard to predict because the process they undergo will determine the metabolic pathway for both components, and this might result in different biological effects in humans. Currently, constituents of exosomes can be consulted in 3 available online databases: Exocarta (Mathivanan et al., 2012), which contains information on the protein, RNA, and lipid exclusively from exosomes of various origins, including human and bovine, and EVpedia (Kim et al., 2015) and Vesiclepedia (Kalra et al., 2012), which are very similar sites that possess databases from all extracellular vesicles, including exosomes.

One important aspect for consideration in using MFGM phospholipids, besides the experimental results of their biological activity, is related to their structure and composition. We have taken a preliminary and superficial look at some of the available commercial and experimental ingredients containing MFGM. Figure 3 is just an example of the very heterogeneous structures produced by different processes (not described due to commercial interests). From observation of these structures, it is evident that their incorporation in different formulations has to follow optimization procedures.

\section{EVIDENCE OF THE ROLE OF MILK PHOSPHOLIPIDS IN INTESTINAL AND BRAIN DEVELOPMENT}

Milk is an optimal source of nutrients for humans due to the wide variety of components secreted by the mammary cells: proteins, carbohydrates, and lipids. These constituents have been well studied, characterized, and thoroughly proven to have a beneficial role in human nutrition. Recent evidence suggests, however, the potential positive role of an additional lipid fraction that was overlooked in the past decades: phospholipids, sphingolipids, and sphingophospholipids. As reviewed above, this group of molecules can be found as the main constituents of vesicular structures in relatively low concentrations in milk and dairy products, synthesized by different mechanisms: MFGM and MEX. So far, clini- 
A

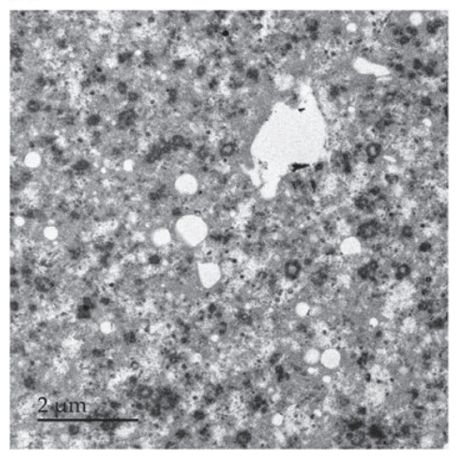

B

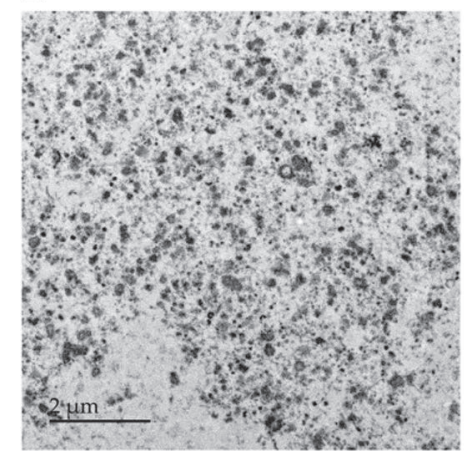

C

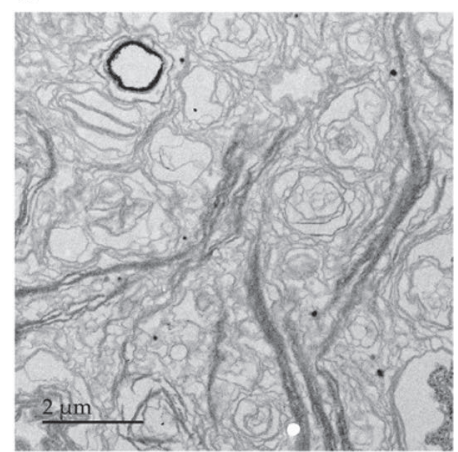

Figure 3. Transmission electron microscopy images of 3 different commercial samples of ingredients containing milk fat globule membrane (MFGM). Samples A, B, and C are from undisclosed commercial ingredient sources. Although we can detect bovine milk origin, the main differences are the total amount of milk phospholipids per gram of powder and the organization into different microstructures.

cal and epidemiological data have provided evidence in animal models that the polar lipid fraction from MFGM affects infant gastrointestinal development. It has been proposed that one possible mechanism to benefit from milk polar lipids may occur via bacteria-lipid interaction, which in turn results in gut microbiome modification (Santiago-Rodriguez et al., 2016). The biochemical pathway that allows gut microbiota to bind lipids and express lipolytic and phospholipolytic enzymes to digest milk fat is currently being explored by our research group through physicochemical and molecular biology experiments. So far we have found that the structure (i.e., liposomes vs. emulsified lipids) and concentration in which the polar lipids are presented to some strains of bacteria such as Lactobacillus determine how the bacterial cells bind these molecules, the preference toward different phospholipid compositions, and the expression of phospholipolytic enzymes once they interact in in vitro systems.

The protective and replenishing effects of MFGM components in the intestinal epithelium of infants altering the gut microbiome was also proven in rat pups (pup-in-a-cup rearing model) fed with 1.2 and $6 \mathrm{~g} / \mathrm{L}$ MFGM for $10 \mathrm{~d}$. Supplementation of the tested formula modified phylum microbiota in the colon, resembling that of the pups fed with mothers' milk instead of harboring a higher percentage of Proteobacteria and a lower percentage of Firmicutes like those fed the control diet, which lacked MFGM lipids (Bhinder et al., 2017). This outstanding work found that a diet deficient in MFGM produced shortfalls in intestinal development compared with mothers' milk, whereas addition of MFGM in the feeding formula restored intestinal growth, assessed by monitoring Paneth and goblet cell numbers as well as tight junction patterns. Moreover, Bhinder et al. (2017) reported a protective aftermath against inflammation caused by Clostridium difficile toxin.
In addition to this important effect on intestinal health in animal models, there is accumulating evidence that MGFM components influence brain development, with high differences compared with formula-fed newborns (Oshida et al., 2003; Gurnida et al., 2012; Tanaka et al., 2013). Polar lipid supplementation could narrow the gap in neuronal functions such as cognitive performance, behavioral development, and myelinationpromoting markers between breastfed and formula-fed infants. Moreover, a recent study has shown that a diet enriched in MFGM components from buttermilk have a positive effect on cognitive decay of aging rats by amelioration of insulin resistance as detected by insulin signaling in the hippocampus and cerebral cortex (Tomé-Carneiro et al., 2018). All these findings even pose the idea that milk polar lipid supplementation has a beneficial effect on neural functions throughout life.

Here we discuss the outcomes of 3 clinical studies (double-blinded randomized controlled trials) in which the effect of milk polar lipid fraction was tested directly on the neuronal, cognitive, or behavioral development of infants without any negative outcome or side effect such as diarrhea or fever. The first study was conducted in Indonesia in 2010 (Gurnida et al., 2012) and was oriented to assess the effect of gangliosides on cognitive development. As reviewed in previous sections, gangliosides are complex sphingolipids that contain at least 1 molecule of sialic acid and diverse carbohydrates. In humans, they are found in the brain, making up approximately $10 \%$ of the total mass of brain lipids. They play an important role in this organ because they participate in the formation of synapses between neural cells and during neural transmission, facilitating the binding of transmitter molecules to the synaptic membranes (Rahmann, 1995). They also contribute to neural growth and are thought to act as substrates for neural layer formation, which generates higher cogni- 
Table 3. Cognitive development mean scores on the Griffiths Mental Development Scale of infants (Griffiths, 1954; McAlinden, 1997) subjected to supplementation with milk gangliosides for $6 \mathrm{mo}^{1}$

\begin{tabular}{|c|c|c|c|c|}
\hline \multirow[b]{2}{*}{ Test (score) } & \multicolumn{3}{|c|}{ Group $^{2}$} & \multirow[b]{2}{*}{$P$-value } \\
\hline & Treatment & Control & Breastfed & \\
\hline Locomotor IQ & 120.0 & 117.2 & 113.7 & 0.225 \\
\hline Personal-social IQ & 121.2 & 119.0 & 115.4 & 0.368 \\
\hline Hearing and speech IQ & 120.3 & 116.7 & 115.1 & 0.114 \\
\hline Hand and eye coordination IQ & 129.5 & 122.0 & 123.9 & 0.006 \\
\hline Performance IQ & 131.1 & 122.2 & 127.8 & $<0.001$ \\
\hline General IQ & 125.4 & 120.6 & 120.0 & 0.041 \\
\hline
\end{tabular}

tive functions in the brain (Rösner, 2003). Previous to this study, it was proven in a piglet model (Wang et al., 2007) that sialic acid supplementation improved memory and learning. Gurnida et al. (2012) evaluated the supplementation of a mixture of milk phospholipids and gangliosides (fundamentally GM3 and GD3) in infant formula on the cognitive development functions of normal, healthy 2- to 8-wk-old infants (Gurnida et al., 2012). After receiving supplementation for 6 mo (24 wk), which is a critical period of brain growth and development, significantly increased cognitive scores were observed (Table 3) as measured by the Griffiths Mental Development Scale (Griffiths, 1954; McAlinden, 1997), which covers a general or total scale and 5 additional scales (all reported as IQ numeric values): locomotor, personal-social, hearing and speech, eye and hand coordination, and performance. The results showed that hand and eye coordination, performance, and general scores were significantly improved and similar to those of breastfed infants compared with the control group, which received a decreased concentration of gangliosides. This suggests that milk ganglioside supplementation may induce advantages in cognitive development, particularly in those aspects related to motor skills, compared with diets or formulas that lack these molecules.

The second study, conducted by Tanaka et al. (2013) in Japan and published a year later, explored the role of milk SM in the neurobehavioral development of infants with very low birth weight given the imperative necessity to optimize their growth and development via dietary sources. It is known that SM contributes to the myelination of the central nervous system in developing rats (Oshida et al., 2003) and alters in a positive way the levels of docosahexaenoic acid, the deficiency of which is implicated in decreased dendritic arborization and impaired expression of the genes that regulate neurogenesis, neurotransmission, and connectivity of neural cells (Hibbeln et al., 2007). The study aimed not only to evaluate the fortification of the feeding formula with milk SM but also to assess the source of polar lipids because the control group was fed a mixture of phospholipids and sphingolipids isolated from egg lecithin (Tanaka et al., 2013).

The main results (Table 4) of the study strongly indicated that after at least 12 mo of feeding, the infants presented improved neurobehavioral scores, measured by different techniques such as the Bayley Scales of Infant Development (2nd ed.), which evaluates mental and psychomotor parameters (Bayley, 1993); the Fagan test for intelligence, which measures novelty rate preference as an indicator of intellectual development (Fagan, 1984); the visual evoked potential test (Hood et al., 2003), which tests the level of myelination and neurotransmission speed via the optic nerves; and the sustained attention test (Colombo et al., 2004) and memory test (Bauer, 1996), which are also indicators of neural development.

These results indicate that a slight increase in SM content in the diet might be positively associated with neurodevelopment in low-weight infants. Early-life nutrition supplemented with SM, among other nutrients, has an important role in promoting myelination and production of neurotransmitter molecules in the brain during early infancy and, consequently, cognitive outcomes (Deoni et al., 2018). It was also stated that milk SM promotes fluidity of neurons and acts in the prefrontal cortex of the brain, given the results from the visual evoked potential, attention, and memory tests (Tanaka et al., 2013). The source of SM and polar lipids was not discussed in the publication, but the authors observed that milk SM administered in the trial group was a safe form of artificial milk compared with egg SM. We believe that the composition and organization of phospholipids and sphingolipids in milk influence the function and resulting effect in human health because they are arranged in a completely different structure than they are in egg (Anton, 2013). 
Table 4. Neurobehavioral mean scores of very-low-weight infants subjected to supplementation with milk sphingomyelin (SM) for $12 \mathrm{mo}^{1}$

\begin{tabular}{|c|c|c|c|}
\hline \multirow[b]{2}{*}{ Test } & \multicolumn{2}{|c|}{ Group $^{2}$} & \multirow[b]{2}{*}{$P$-value } \\
\hline & Treatment & Control & \\
\hline \multicolumn{4}{|c|}{ Bayley Scales of Infant Development (2nd ed.) } \\
\hline Mental development & 97.8 & 91.1 & NS \\
\hline Psychomotor development & 93.8 & 88.8 & NS \\
\hline \multicolumn{4}{|l|}{ Behavior rating scale } \\
\hline Orientation & 65.1 & 44.5 & $<0.01$ \\
\hline Emotional & 69.5 & 43.1 & $<0.01$ \\
\hline Motor quality & 80.9 & 48.0 & $<0.01$ \\
\hline Total score & 76.0 & 47.5 & $<0.01$ \\
\hline \multicolumn{4}{|l|}{ Fagan test } \\
\hline Novelty preference rate $(\%)$ & 50.8 & 44.2 & $<0.01$ \\
\hline \multicolumn{4}{|l|}{ Visual evoked potential test } \\
\hline Latency $(\mathrm{ms})$ & 100.5 & 103.0 & NS \\
\hline \multicolumn{4}{|l|}{ Sustained attention test } \\
\hline Distractive behaviors (no. in 4 min) & 1.7 & 4.4 & $<0.05$ \\
\hline \multicolumn{4}{|l|}{ Memory test } \\
\hline Counts $^{3}$ & 0.8 & 0.3 & NS \\
\hline
\end{tabular}

${ }^{1}$ Reproduced and adapted from Tanaka et al. (2013).

${ }^{2}$ The treatment group $(\mathrm{n}=12)$ received $20 \mathrm{mg}$ of milk SM/100 g of formula. The control group $(\mathrm{n}=12)$ received $13 \mathrm{mg}$ of egg SM/100 g of formula.

${ }^{3}$ Count represents the number of times an infant finds a toy hidden in 1 of 2 cups.

The third study, published by Timby et al. (2014), aimed to test whether supplementation of MFGM components (sialic acid, phospholipids, and phosphosphingolipids) reduced differences in cognitive development and early growth between formula-fed and breastfed infants. The trial took place in Sweden in 2014, where the infants were fed a formula enriched with MFGM $(70 \mathrm{mg} / 100 \mathrm{~mL})$, a control formula with a basal concentration of polar lipids $(30 \mathrm{mg} / 100 \mathrm{~mL})$, or breast milk (Table 5) until 12 mo of age. After that period the infants were tested with the Bayley Scales of Infant and Toddler Development (3rd ed.; Bayley, 2006) using the cognitive, motor, and verbal subscale as an indicator of neural development.

One of the main outcomes was that infants fed an MFGM-supplemented diet obtained a significantly higher cognitive score than the control group (105.8 compared with $101.8 ; P=0.008$ ) but, interestingly, not significantly different from the breastfed group (106.4; $P=0.73$ ). The authors hypothesized that these findings could have been a direct result of either one of the many bioactive components of the MFGM proven to have an essential role in brain development or, more likely, a combination of many components such as SM, gangliosides, phospholipids, and even bioactive membrane proteins (Timby et al., 2014).

\section{CONCLUSIONS}

The information reviewed here highlights the enormous potential of the polar lipid fraction of milk to exert positive effects on the development of infants at

Table 5. Cognitive development mean scores on Bayley Scales of Infant and Toddler Development (Bayley, 2006) of infants subjected to supplementation with milk fat globule membrane (MFGM) for $12 \mathrm{mo}^{1}$

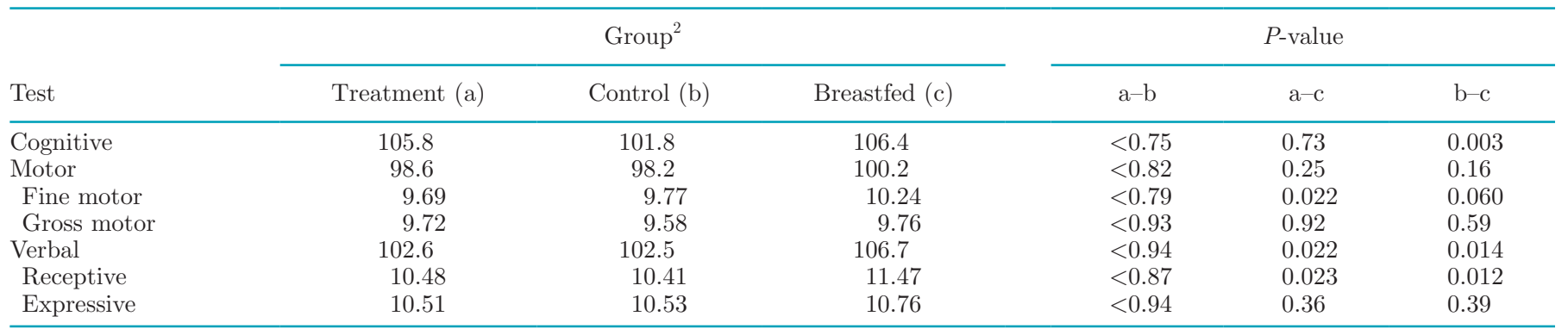

${ }^{1}$ Reproduced and adapted from Timby et al. (2014).

${ }^{2}$ The treatment group $(\mathrm{n}=71)$ received $70 \mathrm{mg}$ of MFGM/100 mL of formula. The control group $(\mathrm{n}=64)$ received $30 \mathrm{mg}$ of polar lipids/100 mL of formula. The breastfed group $(\mathrm{n}=70)$ received breast milk. 
a neuronal level, the known benefits obtained in the regulation of immune responses, and the modulation of intestinal microbiome and protection from bacterial infection. Even though the number of studies is very low and the interventions are heterogeneous, with different concentrations given in different periods of time, this opens a wide possibility of applications and future research, especially with infant nutrition and development of formulations that molecularly have a closer resemblance to the golden standard: breast milk. Another important aspect to highlight is that all of these studies and trials used milk phospholipids, sphingolipids, and gangliosides contained in MFGM. In comparison, no reports to this date are focused on testing the effect of polar lipids from MEX; hence, the scientific base of knowledge is limited. We believe that it is imperative to shed light onto the connection between composition, structure, and function in milk vesicles, whether they are MFGM or MEX phospholipidic components, and to perform not only in vivo or in vitro studies but also chemical and physicochemical characterization, which can help us understand and discuss from a molecular standpoint the functions and bioactivities in living organisms.

\section{ACKNOWLEDGMENTS}

We acknowledge the J. T. Parker Endowed Chair from The Ohio State University (Columbus) for providing funding to assist with this review.

\section{REFERENCES}

Anton, M. 2013. Egg yolk: Structures, functionalities and processes. J. Sci. Food Agric. 93:2871-2880.

Avalli, A., and G. Contarini. 2005. Determination of phospholipids in dairy products by SPE/HPLC/ELSD. J. Chromatogr. A 1071:185-190.

Bauer, P. J. 1996. What do infants recall of their lives? Memory for specific events by one- to two-year-olds. Am. Psychol. 51:29-41.

Bayley, N. 1993. Bayley Scales of Infant Development: Manual. Psychological Corp., New York, NY.

Bayley, N. 2006. Bayley Scales of Infant and Toddler Development. 3rd ed. Harcourt Assessment, San Antonio, TX.

Bhinder, G., J. M. Allaire, C. Garcia, J. T. Lau, J. M. Chan, N. R. Ryz, E. S. Bosman, F. A. Graef, S. M. Crowley, L. S. Celiberto, J. C. Berkmann, R. A. Dyer, K. Jacobson, M. G. Surette, S. M. Innis, and B. A. Vallance. 2017. Milk fat globule membrane supplementation in formula modulates the neonatal gut microbiome and normalizes intestinal development. Sci. Rep. 7:45274.

Bitman, J., and D. L. Wood. 1990. Changes in milk fat phospholipids during lactation. J. Dairy Sci. 73:1208-1216.

Bourlieu, C., K. Bouzerzour, S. Ferret-Bernard, C. Le Bourgot, S. Chever, O. Menard, A. Deglaire, I. Cuinet, P. Le Ruyet, C. Bonhomme, D. Dupont, and I. Le Huerou-Luron. 2015. Infant formula interface and fat source impact on neonatal digestion and gut microbiota. Eur. J. Lipid Sci. Technol. 117:1500-1512.

Christie, W. W. 1987. Simple and complex lipids: Their occurrence, chemistry, and biochemistry. Nat. Prod. Rep. 4:113-128.

Clark, M. R. 2011. Flippin' lipids. Nat. Immunol. 12:373-375.
Claumarchirant, L., A. Cilla, E. Matencio, L. M. Sanchez-Siles, P. Castro-Gomez, J. Fontecha, A. Alegria, and M. J. Lagarda. 2016. Addition of milk fat globule membrane as an ingredient of infant formulas for resembling the polar lipids of human milk. Int. Dairy J. $61: 228-238$.

Colombo, J., K. N. Kannass, D. J. Shaddy, S. Kundurthi, J. M. Maikranz, C. J. Anderson, O. M. Blaga, and S. E. Carlson. 2004. Maternal DHA and the development of attention in infancy and toddlerhood. Child Dev. 75:1254-1267.

Colombo, M., G. Raposo, and C. Thery. 2014. Biogenesis, secretion, and intercellular interactions of exosomes and other extracellular vesicles. Annu. Rev. Cell Dev. Biol. 30:255-289.

Contarini, G., and M. Povolo. 2013. Phospholipids in milk fat: Composition, biological and technological significance, and analytical strategies. Int. J. Mol. Sci. 14:2808-2831.

Deeth, H. C. 1997. The role of phospholipids in the stability of milk fat globules. Aust. J. Dairy Technol. 52:44-46.

Deoni, S., D. Dean, S. Joelson, J. O'Regan, and N. Schneider. 2018 Early nutrition influences developmental myelination and cognition in infants and young children. Neuroimage 178:649-659.

Dewettinck, K., R. Rombaut, N. Thienpont, T. T. Le, K. Messens, and J. Van Camp. 2008. Nutritional and technological aspects of milk fat globule membrane material. Int. Dairy J. 18:436-457.

Evers, J. M. 2004. The milkfat globule membrane-Compositional and structural changes post secretion by the mammary secretory cell. Int. Dairy J. 14:661-674.

Fagan, J. F. 1984. Recognition memory and intelligence. Intelligence $8: 31-36$.

Fedotova, Y., and R. W. Lencki. 2008. The effect of phospholipids on milkfat crystallization behavior. J. Am. Oil Chem. Soc. 85:205212.

French, K. C., M. A. Antonyak, and R. A. Cerione. 2017. Extracellular vesicle docking at the cellular port: Extracellular vesicle binding and uptake. Semin. Cell Dev. Biol. 67:48-55.

Gallier, S., D. Gragson, R. Jimenez-Flores, and D. Everett. 2010. Using confocal laser scanning microscopy to probe the milk fat globule membrane and associated proteins. J. Agric. Food Chem. 58:4250-4257.

Gallier, S., A. Laubscher, and R. Jimenez-Flores. 2014. The milk fat globule membrane: Structure, methodology for its study, and functionality. Pages 107-142 in Food Structures, Digestion and Health, 1st ed. M. Boland, M. Golding, and H. Singh, ed. Academic Press, Cambridge, MA.

Garcia, C., N. W. Lutz, S. Confort-Gouny, P. J. Cozzone, M. Armand, and M. Bernard. 2012. Phospholipid fingerprints of milk from different mammalians determined by P-31 NMR: Towards specific interest in human health. Food Chem. 135:1777-1783.

Garner, A. E., D. A. Smith, and N. M. Hooper. 2007. Sphingomyelin chain length influences the distribution of GPI-anchored proteins in rafts in supported lipid bilayers. Mol. Membr. Biol. 24:233-242.

Graves, E. L., A. D. Beaulieu, and J. K. Drackley. 2007. Factors affecting the concentration of sphingomyelin in bovine milk. J. Dairy Sci. 90:706-715.

Griffiths, R. 1954. The Abilities of Babies: A Study in Mental Measurement. McGraw-Hill, New York, NY.

Gurnida, D. A., A. M. Rowan, P. Idjradinata, D. Muchtadi, and N. Sekarwana. 2012. Association of complex lipids containing gangliosides with cognitive development of 6-month-old infants. Early Hum. Dev. 88:595-601.

Guyomarc'h, F., M. H. Chen, O. Et-Thakafy, S. Zou, and C. Lopez. 2017. Gel-gel phase separation within milk sphingomyelin domains revealed at the nanoscale using atomic force microscopy. Biomembranes 1859:949-958.

Guyomarc'h, F., S. Zou, M. H. Chen, P. E. Milhiet, C. Godefroy, V. Vie, and C. Lopez. 2014. Milk sphingomyelin domains in biomimetic membranes and the role of cholesterol: Morphology and nanomechanical properties investigated using AFM and force spectroscopy. Langmuir 30:6516-6524.

Hankins, H. M., R. D. Baldridge, P. Xu, and T. R. Graham. 2015. Role of flippases, scramblases and transfer proteins in phosphatidylserine subcellular distribution. Traffic 16:35-47. 
Hata, T., K. Murakami, H. Nakatani, Y. Yamamoto, T. Matsuda, and N. Aoki. 2010. Isolation of bovine milk-derived microvesicles carrying mRNAs and microRNAs. Biochem. Biophys. Res. Commun. 396:528-533.

Hazotte, A., D. Libong, and P. Chaminade. 2007. High-temperature micro liquid chromatography for lipid molecular species analysis with evaporative light scattering detection. J. Chromatogr. A 1140:131-139.

Hibbeln, J. R., J. M. Davis, C. Steer, P. Emmett, I. Rogers, C. Williams, and J. Golding. 2007. Maternal seafood consumption in pregnancy and neurodevelopmental outcomes in childhood (ALSPAC study): An observational cohort study. Lancet 369:578-585.

Hood, D. C., J. C. Odel, and B. J. Winn. 2003. The multifocal visual evoked potential. J. Neuroophthalmol. 23:279-289.

Jimenez-Flores, R., I. Higuera-Ciapara, and Y. Pouliot. 2009. Beverages based on milk fat globule membrane (MFGM) and other novel concepts for dairy-based functional beverages. Pages 281-296 in Functional and Specialty Beverage Technology. P. Paquin, ed. Woodhead, Cambridge, UK.

Kalra, H., G. P. C. Drummen, and S. Mathivanan. 2016. Focus on extracellular vesicles: Introducing the next small big thing. Int. J. Mol. Sci. 17:170.

Kalra, H., R. J. Simpson, H. Ji, E. Aikawa, P. Altevogt, P. Askenase, V. C. Bond, F. E. Borras, X. Breakefield, V. Budnik, E. Buzas, G. Camussi, A. Clayton, E. Cocucci, J. M. Falcon-Perez, S. Gabrielsson, Y. S. Gho, D. Gupta, H. C. Harsha, A. Hendrix, A. F. Hill, J. M. Inal, G. Jenster, E. M. Kramer-Albers, S. K. Lim, A. Llorente, J. Lotvall, A. Marcilla, L. Mincheva-Nilsson, I. Nazarenko, R. Nieuwland, E. N. M. Hoen, A. Pandey, T. Patel, M. G. Piper, S. Pluchino, T. S. K. Prasad, L. Rajendran, G. Raposo, M. Record, G. E. Reid, F. Sanchez-Madrid, R. M. Schiffelers, P. Siljander, A. Stensballe, W. Stoorvogel, D. Taylor, C. Thery, H. Valadi, B. W. M. van Balkom, J. Vazquez, M. Vidal, M. H. M. Wauben, M. Yanez-Mo, M. Zoeller, and S. Mathivanan. 2012. Vesiclepedia: A compendium for extracellular vesicles with continuous community annotation. PLoS Biol. 10:e1001450.

Keenan, T. W., and I. H. Mather. 2006. Intracellular origin of milk fat globules and the nature of the milk fat globule membrane. Pages 137-171 in Advanced Dairy Chemistry. Vol. 2. Lipids. P. F. Fox and P. L. H. McSweeney, ed. Springer, Boston, MA.

Kiełbowicz, G., P. Micek, and C. Wawrzenczyk. 2013. A new liquid chromatography method with charge aerosol detector (CAD) for the determination of phospholipid classes. Application to milk phospholipids. Talanta 105:28-33.

Kim, D. K., J. Lee, S. R. Kim, D. S. Choi, Y. J. Yoon, J. H. Kim, G. Go, D. Nhung, K. Hong, S. C. Jang, S. H. Kim, K. S. Park, O. Y. Kim, H. T. Park, J. H. Seo, E. Aikawa, M. Baj-Krzyworzeka, B. W. M. van Balkom, M. Belting, L. Blanc, V. Bond, A. Bongiovanni, F. E. Borras, L. Buee, E. I. Buzas, L. Cheng, A. Clayton, E. Cocucci, C. S. Dela Cruz, D. M. Desiderio, D. Di Vizio, K. Ekstrom, J. M. Falcon-Perez, C. Gardiner, B. Giebel, D. W. Greening, J. C. Gross, D. Gupta, A. Hendrix, A. F. Hill, M. M. Hill, E. N. Hoen, D. W. Hwang, J. Inal, M. V. Jagannadham, M. Jayachandran, Y. K. Jee, M. Jorgensen, K. P. Kim, Y. K. Kim, T. Kislinger, C. Lasser, D. S. Lee, H. Lee, J. van Leeuwen, T. Lener, M. L. Liu, J. Lotvall, A. Marcilla, S. Mathivanan, A. Moller, J. Morhayim, F. Mullier, I. Nazarenko, R. Nieuwland, D. N. Nunes, K. Pang, J. Park, T. Patel, G. Pocsfalvi, H. del Portillo, U. Putz, M. I. Ramirez, M. L. Rodrigues, T. Y. Roh, F. Royo, S. Sahoo, R. Schiffelers, S. Sharma, P. Siljander, R. J. Simpson, C. Soekmadji, P. Stahl, A. Stensballe, E. Stepien, H. Tahara, A. Trummer, H. Valadi, L. J. Vella, S. N. Wai, K. Witwer, M. Yanez-Mo, H. Youn, R. Zeidler, and Y. S. Gho. 2015. EVpedia: A community web portal for extracellular vesicles research. Bioinformatics 31:933-939.

Kusuma, R. J., S. Manca, T. Friemel, S. Sukreet, C. Nguyen, and J. Zempleni. 2016. Human vascular endothelial cells transport foreign exosomes from cow's milk by endocytosis. Am. J. Physiol. Cell Physiol. 310:C800-C807.

Lakkaraju, A., and E. Rodriguez-Boulan. 2008. Itinerant exosomes: Emerging roles in cell and tissue polarity. Trends Cell Biol. 18:199-209.
Le, T. T., J. Miocinovic, T. M. Nguyen, R. Rombaut, J. van Camp, and K. Dewettinck. 2011. Improved solvent extraction procedure and high-performance liquid chromatography-evaporative lightscattering detector method for analysis of polar lipids from dairy materials. J. Agric. Food Chem. 59:10407-10413.

Lopez, C., V. Briard-Bion, O. Menard, F. Rousseau, P. Pradel, and J. M. Besle. 2008. Phospholipid, sphingolipid, and fatty acid compositions of the milk fat globule membrane are modified by diet. J. Agric. Food Chem. 56:5226-5236.

Lopez, C., M. N. Madec, and R. Jimenez-Flores. 2010. Lipid rafts in the bovine milk fat globule membrane revealed by the lateral segregation of phospholipids and heterogeneous distribution of glycoproteins. Food Chem. 120:22-33.

Ma, L., X. Liu, A. K. MacGibbon, A. Rowan, P. McJarrow, and B. Y. Fong. 2015. Lactational changes in concentration and distribution of ganglioside molecular species in human breast milk from Chinese mothers. Lipids 50:1145-1154.

Mathivanan, S., C. J. Fahner, G. E. Reid, and R. J. Simpson. 2012. ExoCarta 2012: Database of exosomal proteins, RNA and lipids. Nucleic Acids Res. 40:D1241-D1244.

McAlinden, P. 1997. The Griffiths mental development scale (babies) from birth to 2 years. Public Health 111:347-348.

Murthy, A. V. R., F. Guyomarc'h, and C. Lopez. 2016. Cholesterol decreases the size and the mechanical resistance to rupture of sphingomyelin rich domains, in lipid bilayers studied as a model of the milk fat globule membrane. Langmuir 32:6757-6765.

Nieuwland, R., and A. Sturk. 2010. Why do cells release vesicles? Thromb. Res. 125(Suppl. 1):S49-S51.

Oshida, K., T. Shimizu, M. Takase, Y. Tamura, T. Shimizu, and Y. Yamashiro. 2003. Effects of dietary sphingomyelin on central nervous system myelination in developing rats. Pediatr. Res. 53:589-593.

Pimentel, L., A. L. Fontes, S. Salsinha, M. Machado, I. Correia, A. M. Gomes, M. Pintado, and L. M. Rodriguez-Alcala. 2018. Suitable simple and fast methods for selective isolation of phospholipids as a tool for their analysis. Electrophoresis 39:1835-1845.

Rahmann, H. 1995. Brain gangliosides and memory formation. Behav. Brain Res. 66:105-116.

Rani, P., V. R. Yenuganti, S. Shandilya, S. K. Onteru, and D. Singh. 2017. miRNAs: The hidden bioactive component of milk. Trends Food Sci. Technol. 65:94-102.

Rombaut, R., J. V. Camp, and K. Dewettinck. 2005. Analysis of phospho- and sphingolipids in dairy products by a new HPLC method. J. Dairy Sci. 88:482-488.

Rombaut, R., and K. Dewettinck. 2006. Properties, analysis and purification of milk polar lipids. Int. Dairy J. 16:1362-1373.

Rombaut, R., K. Dewettinck, and J. Van Camp. 2007. Phospho- and sphingolipid content of selected dairy products as determined by HPLC coupled to an evaporative light scattering detector (HPLCELSD). J. Food Compos. Anal. 20:308-312.

Rombaut, R., J. V. Van Camp, and K. Dewettinck. 2006. Phosphoand sphingolipid distribution during processing of milk, butter and whey. Int. J. Food Sci. Technol. 41:435-443.

Rösner, H. 2003. Developmental expression and possible roles of gangliosides in brain development. Prog. Mol. Subcell. Biol. 32:49-73.

Rueda, R. 2013. Gangliosides, immunity, infection and inflammation. Pages $341-358$ in Diet, Immunity and Inflammation. P. C. Calder and P. Yaqoob, ed. Woodhead, Cambridge, UK.

Sanchez-Juanes, F., J. M. Alonso, L. Zancada, and P. Hueso. 2009. Distribution and fatty acid content of phospholipids from bovine milk and bovine milk fat globule membranes. Int. Dairy J. 19:273278.

Santiago-Rodriguez, T. M., R. Cano, and R. Jimenez-Flores. 2016. Potential applications of metagenomics to assess the biological effects of food structure and function. Food Funct. 7:4160-4169.

Singh, H., and S. Gallier. 2017. Nature's complex emulsion: The fat globules of milk. Food Hydrocoll. 68:81-89.

Skotland, T., K. Sandvig, and A. Llorente. 2017. Lipids in exosomes: Current knowledge and the way forward. Prog. Lipid Res. 66:3041. 
Spitsberg, V. L., and R. C. Gorewit. 1997. In vitro phosphorylated bovine milk fat globule membrane proteins. J. Nutr. Biochem. 8:181-189.

Subra, C., D. Grand, K. Laulagnier, A. Stella, G. Lambeau, M. Paillasse, P. De Medina, B. Monsarrat, B. Perret, S. Silvente-Poirot, M. Poirot, and M. Record. 2010. Exosomes account for vesiclemediated transcellular transport of activatable phospholipases and prostaglandins. J. Lipid Res. 51:2105-2120.

Tanaka, K., M. Hosozawa, N. Kudo, N. Yoshikawa, K. Hisata, H. Shoji, K. Shinohara, and T. Shimizu. 2013. The pilot study: Sphingomyelin-fortified milk has a positive association with the neurobehavioural development of very low birth weight infants during infancy, randomized control trial. Brain Dev. 35:45-52.

Timby, N., E. Domellof, O. Hernell, B. Lonnerdal, and M. Domellof. 2014. Neurodevelopment, nutrition, and growth until 12 mo of age in infants fed a low-energy, low-protein formula supplemented with bovine milk fat globule membranes: A randomized controlled trial. Am. J. Clin. Nutr. 99:860-868.

Tomé-Carneiro, J., M. Carmen Crespo, E. Burgos-Ramos, C. TomasZapico, A. Garcia-Serrano, P. Castro-Gomez, C. Venero, I. PeredaPerez, S. Baliyan, A. Valencia, J. Fontecha, A. Davalos, and F. Visioli. 2018. Buttermilk and krill oil phospholipids improve hippocampal insulin resistance and synaptic signaling in aged rats. Mol. Neurobiol. 55:7285-7296. van Meer, G., D. R. Voelker, and G. W. Feigenson. 2008. Membrane lipids: Where they are and how they behave. Nat. Rev. Mol. Cell Biol. 9:112-124.

Vanderghem, C., F. Francis, S. Danthine, C. Deroanne, M. Paquot, E. De Pauw, and C. Blecker. 2011. Study on the susceptibility of the bovine milk fat globule membrane proteins to enzymatic hydrolysis and organization of some of the proteins. Int. Dairy J. 21:312-318.

Wang, B., B. Yu, M. Karim, H. H. Hu, Y. Sun, P. McGreevy, P. Petocz, S. Held, and J. Brand-Miller. 2007. Dietary sialic acid supplementation improves learning and memory in piglets. Am. J. Clin. Nutr. 85:561-569.

Wilson, N. L., L. J. Robinson, A. Donnet, L. Bovetto, N. H. Packer, and N. G. Karlsson. 2008. Glycoproteomics of milk: Differences in sugar epitopes on human and bovine milk fat globule membranes. J. Proteome Res. 7:3687-3696.

Zempleni, J., A. Aguilar-Lozano, M. Sadri, S. Sukreet, S. Manca, D. Wu, F. Zhou, and E. Mutai. 2017. Biological activities of extracellular vesicles and their cargos from bovine and human milk in humans and implications for infants. J. Nutr. 147:3-10.

Zhang, Z., C. X. Wang, T. Li, Z. Liu, and L. J. Li. 2014. Comparison of ultracentrifugation and density gradient separation methods for isolating Tca8113 human tongue cancer cell line-derived exosomes. Oncol. Lett. 8:1701-1706. 